03

\title{
О влиянии поперечного профилирования каналов на термомеханику пульсирующих потоков
}

\author{
(С Ю.М. Бродов, Б.П. Жилкин, Л.В. Плотников \\ Уральский федеральный университет им. первого Президента России Б.Н. Ельцина, \\ 620002 Екатеринбург, Россия \\ ฯ e-mail: plotnikovlv@mail.ru
}

(Поступило в Редакцию 14 марта 2017 г. В окончательной редакции 11 сентября 2017 г.)

\begin{abstract}
Проверена гипотеза о том, что одним из методов влияния на тепломеханические характеристики пульсирующих потоков в газовоздушных системах энергетических машин может быть поперечное профилирование каналов. Представлены результаты физического моделирования газодинамики и локальной теплоотдачи во впускных и выпускных каналах разной конфигурации в условиях газодинамической нестационарности применительно к поршневым двигателям внутреннего сгорания. Установлено, что поперечное профилирование трубопроводов стабилизирует газовые потоки в газовоздушных системах двигателей. Показано, что поперечное профилирование впускных и выпускных трубопроводов приводит к снижению интенсивности локальной теплоотдачи на величину до $30 \%$ в зависимости от начальных условий.
\end{abstract}

DOI: $10.21883 /$ JTF.2018.03.45586.2252

\section{Введение}

Известно, что в газовоздушных системах энергетических машин (например, поршневых двигателей внутреннего сгорания или газотурбинных установок) могут образовываться застойные зоны и/или обратные течения, которые отрицательно влияют на гидравлическое сопротивление систем и теплообмен потоков со стенками трубопроводов [1,2]. Это, в свою очередь, ухудшает газодинамические, расходные и теплообменные характеристики рассматриваемых систем. Один из способов совершенствования тепломеханических характеристик газовых потоков заключается в использовании каналов с поперечными сечениями, отличными от круглого, в частности, квадратные или треугольные [3].

Одной из самых распространенных энергетических установок является поршневой двигатель внутреннего сгорания (ДВС). Известно, что более $80 \%$ всей мировой энергии вырабатывается именно поршневыми двигателями [4]. Поэтому улучшение тепломеханических показателей газовых потоков во впускных и выпускных системах с целью повышение эффективности и надежности поршневых двигателей является актуальной задачей мировой энергетики.

\section{Постановка задачи исследования}

В российской и зарубежной литературе можно найти лишь ограниченное количество информации об экспериментальных исследованиях теплообмена во впускных и выпускных системах ДВС в условиях газодинамической нестационарности. Это можно объяснить сложностью объекта исследования - газовые потоки в газовоздушных системах поршневых двигателей являются пульсационными (с частотой $10-100 \mathrm{~Hz}$ и более). Следует отметить, что пульсации потоков во впускной и выпускной системах создаются вынужденно и их период определяется исключительно частотой вращения коленчатого вала. В настоящем исследовании частота вращения коленчатого вала $n$ изменялась в диапазоне от 600 до $3000 \mathrm{rpm}$, т.е. частоты пульсаций потоков в системах составляли от 10 до $50 \mathrm{~Hz}$.

Особенности пульсаций потоков, характерные для рабочих циклов ДВС, состоят в том, что течение на довольно длительное время полностью прекращается под действием клапанного механизма (сечение канала перекрывается), а потом вновь восстанавливается, когда после паузы открывается клапан. В обычных условиях работы поршневых двигателей продолжительность времени, в течение которого клапан открыт (процесс впуска воздуха в цилиндр), составляет около $40 \%$ от времени всего цикла. Остальное время клапан находился в закрытом положении и соответственно воздух в канал не поступает. Для выпускной системы продолжительность времени открытого клапана (процесс выпуска газа из цилиндра) составляет и того меньшую величину примерно 34\% от времени цикла. При этом время цикла также зависит от частоты вращения коленчатого вала и в данном исследовании оно находилось в диапазоне от $0.04 \mathrm{~s}$ (при $n=3000 \mathrm{rpm}$ ) до $0.2 \mathrm{~s}$ (при $n=600 \mathrm{rpm})$.

Другая важная особенность пульсирующих потоков в газовоздушных системах поршневых двигателей, определяющая газодинамические условия теплообмена со стенками каналов, состоит в наличии возвратных течений в них. Это явление во впускной системе объясняется тем, что двигающийся по инерции газовый поток отражается от закрытого клапана и начинает двигаться в обратном 
направлении. При этом вблизи клапана возникает область разрежения, которая заставляет поток вернуться обратно с последующим повторным отражением, и так далее [5].

Также следует подчеркнуть, что физические механизмы течений в процессе впуска воздуха в цилиндр и процессе выпуска газов из цилиндра принципиально отличаются друг от друга. Если движущим фактором течения воздуха в процессе впуска является разрежение, которое создается в цилиндре поршнем, движущимся сверху вниз, т.е. формируются волны разрежения, то в процессе выпуска газов из цилиндра физическая картина обратная - источником движения воздуха является избыточное давление в цилиндре, т.е. после открытия выпускного клапана возникают волны сжатия. Здесь уместно подчеркнуть, что волны разрежения в дозвуковой области являются устойчивыми, а волны сжатия неустойчивыми [6].

В настоящей работе представлены результаты экспериментального исследования газодинамики и локальной теплоотдачи во впускных и выпускных системах разной конфигурации для поршневых двигателей внутреннего сгорания.

В прикладном аспекте данные о тепломеханических характеристиках пульсирующих потоков необходимы для расчета тепловых процессов во время впуска и выпуска и для определения температурных напряжений в основных деталях газовоздушных систем поршневых двигателей. На сегодняшний день эти данные особенно актуальны ввиду того, что зачастую инженерно-технические расчеты производятся в виде оценок по показателям стационарных продувок. Вместе с тем известно, что коэффициент теплоотдачи потока в нестационарных условиях может отличаться от стационарного случая в 2-4 раза [7-11]. Следует иметь в виду, что нестационарность существенно влияет на механизм процессов переноса, поскольку чем глубже нестационарность, тем существеннее неравновесность [12].

\section{Экспериментальные установки и средства измерений}

В настоящей работе объектом исследования являлся пульсирующий газовый поток, движущийся в гидравлических системах с конфигурациями, характерными для впускных и выпускных систем поршневых двигателей.

Для физического моделирования газодинамики и локальной теплоотдачи в пульсирующих потоках во впускных и выпускных системах были разработаны и изготовлены экспериментальные установки, представляющие собой натурные модели одноцилиндрового поршневого двигателя. В качестве прототипа использовался автомобильный двигатель ВАЗ-ОКА (с диаметром цилиндра $82 \mathrm{~mm}$ и ходом поршня $71 \mathrm{~mm})$. Фазы газораспределения (моменты открытия и закрытия клапанов) устано- вок соответствовали таковым для двигателя-прототипа. Привод коленчатого вала установок осуществлялся с помощью электродвигателей, частота вращения которых регулировалась преобразователем частоты в диапазоне от 600 до $3000 \mathrm{rpm}$. Подробное описание экспериментальных установок представлено в [3].

Для проведения исследований на базе аналого-цифрового преобразователя создана автоматизированная система измерений, передающая экспериментальные данные в специализированные программы для обработки. Для определения мгновенных значений скорости потока воздуха $\left(w_{x}\right)$ и локального коэффициента теплоотдачи $\left(\alpha_{x}\right)$ использовался термоанемометр постоянной температуры авторской разработки [13]. Чувствительным элементом датчиков термоанемометра в обоих случаях была нихромовая нить диаметром $5 \mu \mathrm{m}$ и длиной $5 \mathrm{~mm}$. Метод термоанемометрии для исследования газодинамики и локальной теплоотдачи газовых потоков был выбран на основе анализа литературы по экспериментальному исследованию турбулентных потоков, в частности [14-17], и сложившихся подходов к изучению нестационарных течений. Применимость метода термоанемометрии для исследования процессов в газовоздушных системах поршневых двигателей обоснована в классических работах [1,2]. Максимальная систематическая погрешность измерения скорости $\left(w_{x}\right)$ составляла $5.4 \%$, локального коэффициента теплоотдачи $\left(\alpha_{x}\right)-$ $10.0 \%$.

\section{Газодинамика и локальная теплоотдача во впускной системе}

Анализ результатов экспериментального исследования газодинамики и локальной теплоотдачи во впускных и выпускных системах поршневых двигателей проводился раздельно.

В области двигателестроения для обеспечения равномерного поля скоростей во впускных и выпускных системах поршневых двигателей обычно применяют трубопроводы с круглой или слегка овальной формой поперечного сечения. Вместе с тем известно, что в каналах, лишенных полной симметрии, возникают вторичные, продольные, вихревые течения $[18,19]$, которые оказывают существенное влияние на основной поток. На основании этого была выдвинута гипотеза о том, что поперечное профилирование каналов может послужить одним из методов газодинамического совершенствования процессов во впускных и выпускных системах поршневых двигателей.

В настоящем исследовании применялись впускные трубопроводы с профилированными участками с поперечными сечениями в форме круга, квадрата и равностороннего треугольника. Во всех случаях эквивалентный (гидравлический) диаметр $d_{e}$ равнялся $32 \mathrm{~mm}$, а длина профилированного участка составляла приблизительно 30\% от общей длины впускной системы. На рис. 1 по- 


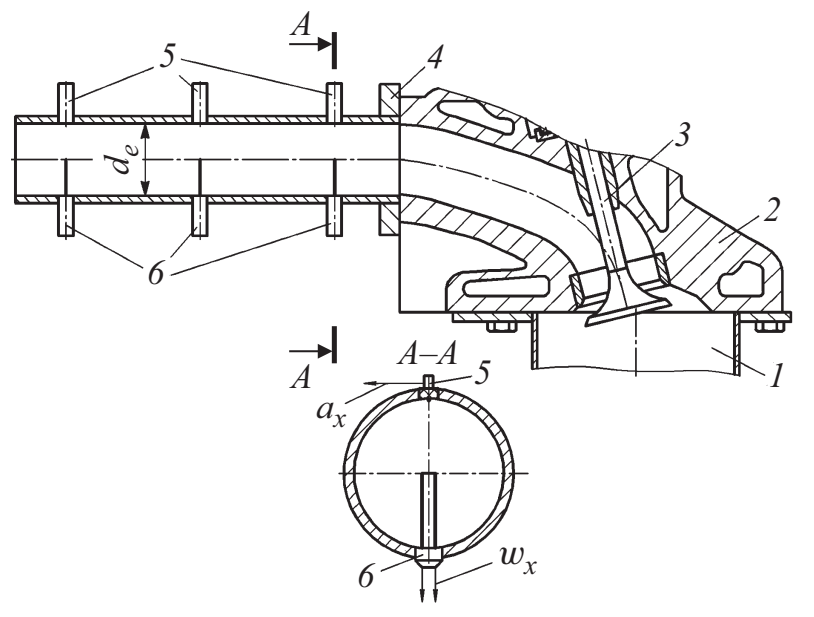

Рис. 1. Конфигурация исследуемой гидравлической системы: 1 - цилиндр, 2 - головка цилиндра, 3 - клапан, 4 опытный трубопровод, 5 - датчик термоанемометра для определения локального коэффициента теплоотдачи, 6 - датчик термоанемометра для определения местной скорости потока газа.
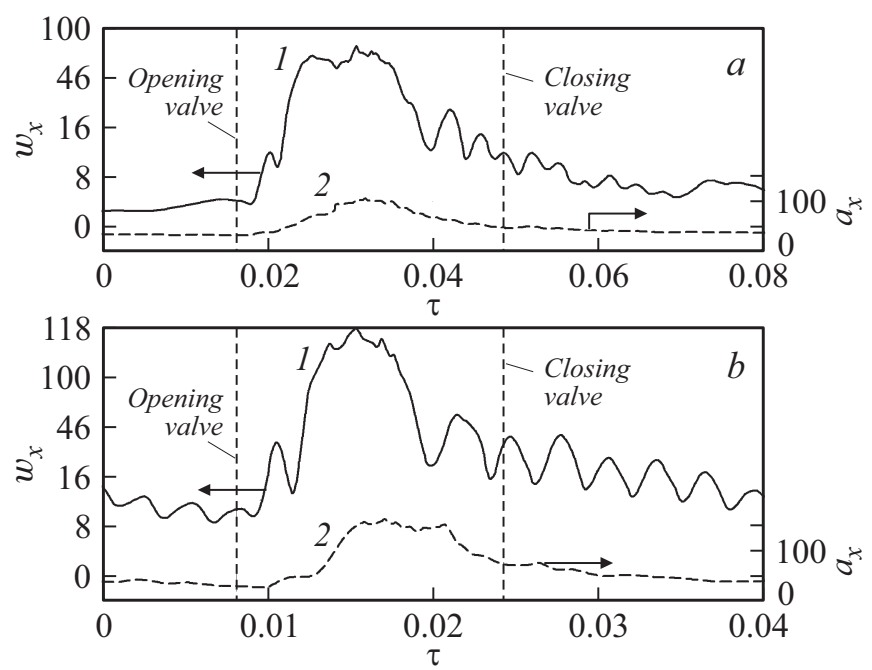

Рис. 2. Зависимости локальных $\left(l_{x}=110 \mathrm{~mm}\right)$ скорости потока воздуха $w_{x}(1)$ и коэффициента теплоотдачи $\alpha_{x}(2)$ от времени $\tau$ во впускном трубопроводе круглого поперечного сечения при разных частотах вращения $n: a-n=1500 \mathrm{rpm}$; $b-n=3000 \mathrm{rpm}$.

казана обобщенная конфигурация исследуемого участка впускной системы экспериментальной установки и места установки датчиков термоанемометра.

На основе физического моделирования установлено, что после закрытия впускного клапана (завершения процесса впуска) наблюдаются сильные колебательные явления скорости потока воздуха, которые усиливаются с ростом частоты вращения коленчатого вала двигателя (рис. 2). Следует отметить, что они наиболее характерны для традиционного впускного трубопровода с круглым поперечным сечением. Физический механизм рассмат- риваемых возвратных колебательных явлений описан выше.

Установлено, что в случае использования во впускном трубопроводе треугольного профилированного участка происходит более быстрое гашение колебательных явлений после закрытия клапана (рис. 3). По мнению авторов, это связано со стабилизирующим влиянием продольных вихревых структур, образующихся в углах треугольного канала. Аналогичная стабилизация течения наблюдается и во впускном трубопроводе с квадратным сечением.

Как и следовало ожидать, эффект стабилизации пульсирующего потока оказывает влияние на расходные характеристики через впускную систему поршневого двигателя. Установлено, что за счет поперечного профилирования каналов происходит увеличение объемного расхода воздуха через впускную систему в среднем на 22\% [20]. Последующее численное моделирование рабочего процесса ДВС показало, что это приводит к увеличению мощности двигателя примерно на $15 \%$.

Соответственно можно предположить, что существенное изменение газодинамических условий во впускной системе окажет влияние на зависимости локального коэффициента теплоотдачи.

Было выявлено зависящее от частоты вращения $n$ запаздывание локальной теплоотдачи от вариации скорости потока воздуха во времени (рис. 2 и 3). С ростом частоты вращения коленчатого вала величина запаздывания $\alpha_{x}$ от $w_{x}$ уменьшается. По мнению авторов, это свидетельствует о том, что начиная с $n=1500 \mathrm{rpm} \mathrm{в}$ пограничном слое формируются более активные турбулентные структуры, ускоряющие динамику процесса теплоотдачи. Следует отметить, что величина запазды-

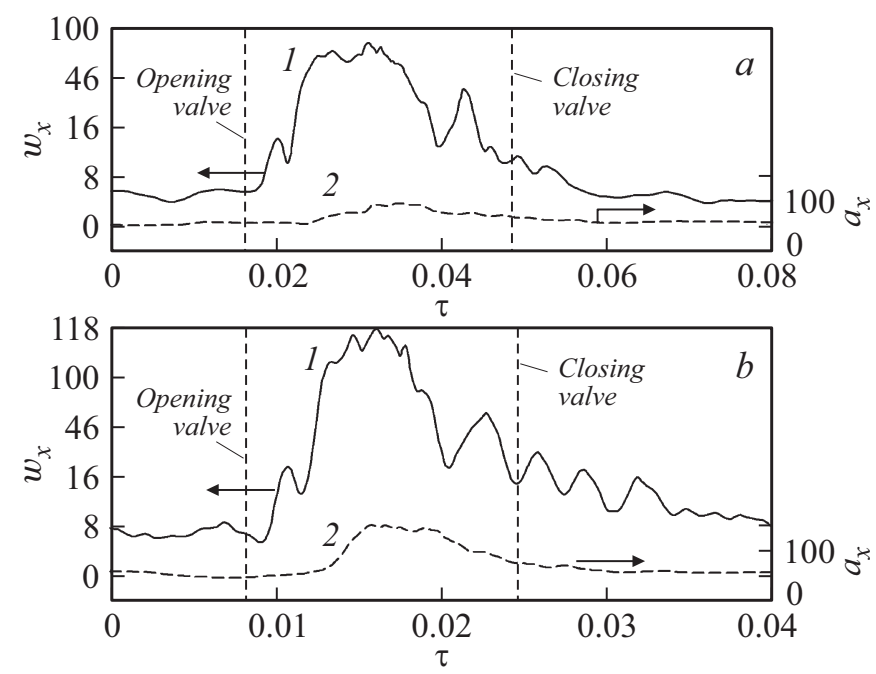

Рис. 3. Зависимости локальных $\left(l_{x}=110 \mathrm{~mm}\right)$ скорости потока воздуха $w_{x}(1)$ и коэффициента теплоотдачи $\alpha_{x}(2)$ от времени $\tau$ во впускном трубопроводе с участком с треугольным поперечным сечением при разных частотах вращения $n$ : $a-n=1500 \mathrm{rpm} ; b-n=3000 \mathrm{rpm}$. 

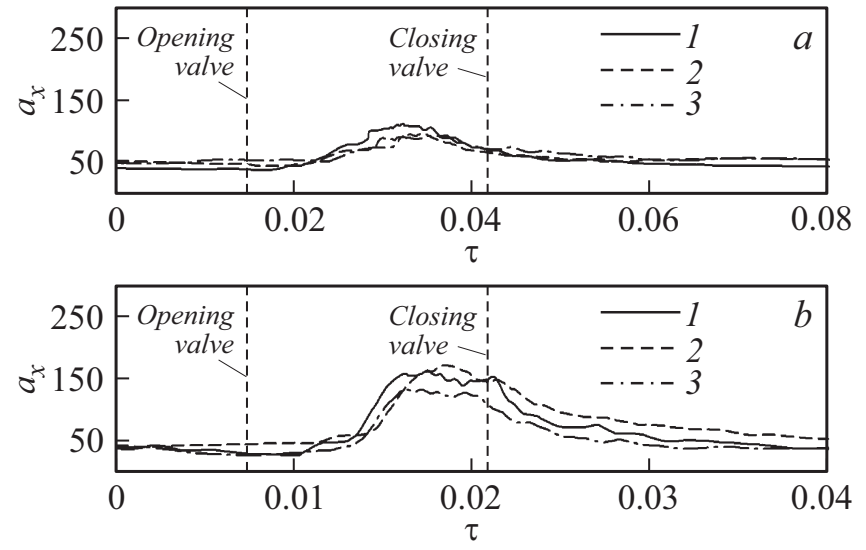

Рис. 4. Зависимость мгновенного локального $\left(l_{x}=110 \mathrm{~mm}\right)$ коэффициента теплоотдачи $\alpha_{x}$ от времени $\tau$ во впускном трубопроводе с разными профилированными участками при разных частотах вращения $n: a-n=1500 \mathrm{rpm} ; \quad b-$ $n=3000 \mathrm{rpm}$. Поперечное сечение участка: 1 - круг, $2-$ квадрат, 3 - треугольник.

вания уменьшается при использовании трубопроводов с профилированными участками.

Характер изменения теплоотдачи во времени оказывает существенное влияние на уровень температурных напряжений в конструктивных элементах газовоздушных систем. Более наглядно можно проследить влияние поперечного профилирования каналов впускной системы на локальный коэффициент теплоотдачи по рис. 4.

Из представленных данных видно, что при всех конфигурациях впускного трубопровода сохраняется общая закономерность изменения локального коэффициента теплоотдачи: области начала и окончания существенного изменения $\alpha_{x}^{\prime}$, область максимальных значений $\alpha_{x}$, вид кривой $\alpha_{x}=f(\tau)$. Следует отметить, что максимальные значения локального коэффициента теплоотдачи несколько меньше при использовании профилированных участков, особенно это характерно для трубопровода с треугольным поперечным сечением. Установлено, что наибольший спад наблюдается для высоких значений частот вращения коленчатого вала - отличия находятся в диапазоне 10-20\%. Такое соотношение интенсивности теплоотдачи характерно для всех исследуемых сечений. Примечательно, что на низких частотах вращения коленчатого вала влияние формы поперечного сечения профилированного участка практически отсутствует (рис. 4, a), т.е. разброс значений локального коэффициента теплоотдачи для всех конфигураций трубопровода находится в пределах систематической погрешности измерений. Более существенные отличия коэффициентов $\alpha_{x}$ можно отметить при средних $(n=1500 \mathrm{rpm})$ и высоких $(n=3000 \mathrm{rpm})$ частотах вращения коленчатого вала (рис. $4, b)$.

На основании полученных данных можно сделать вывод о том, что поперечное профилирование впускных каналов стабилизирует пульсирующие течение в них и снижает интенсивность локальной теплоотдачи. Применительно к поршневым двигателям стабилизация течения должна улучшить наполнение цилиндра воздухом, и соответственно повысится мощность двигателя. В свою очередь снижение интенсивности $\alpha_{x}$ должно положительно сказаться на рабочем процессе ДВС, поскольку оно приведет к меньшему подогреву воздуха от стенок впускного трубопровода, следовательно, увеличится массовый расход воздуха. Также следует отметить, что снижение интенсивности локальной теплоотдачи при использовании профилированных участков во впускном трубопроводе окажет положительное влияние на его тепловую напряженность, т.е. повысится надежность элементов впускной системы двигателя.

\section{Газодинамика и локальная теплоотдача в выпускной системе}

Аналогичным образом выполнено физическое моделирование газодинамики и локальной теплоотдачи в выпускных трубопроводах поршневых двигателей.

Напомним, что принципиальное отличие течения газовых потоков в выпускной системе ДВС от впускной состоит в том, что его движущим фактором является избыточное давление в цилиндре (волны сжатия), которое превышает атмосферное давление в 2-4 раза. В настоящей работе экспериментальные исследования газодинамики и теплообмена в выпускной системе проводились при постоянных начальных избыточных давлениях на выпуске (в цилиндре) $p_{b}$ от 0.05 до $0.2 \mathrm{MPa}$. Температура воздуха в подающей магистрали составляла $35-45^{\circ} \mathrm{C}$.
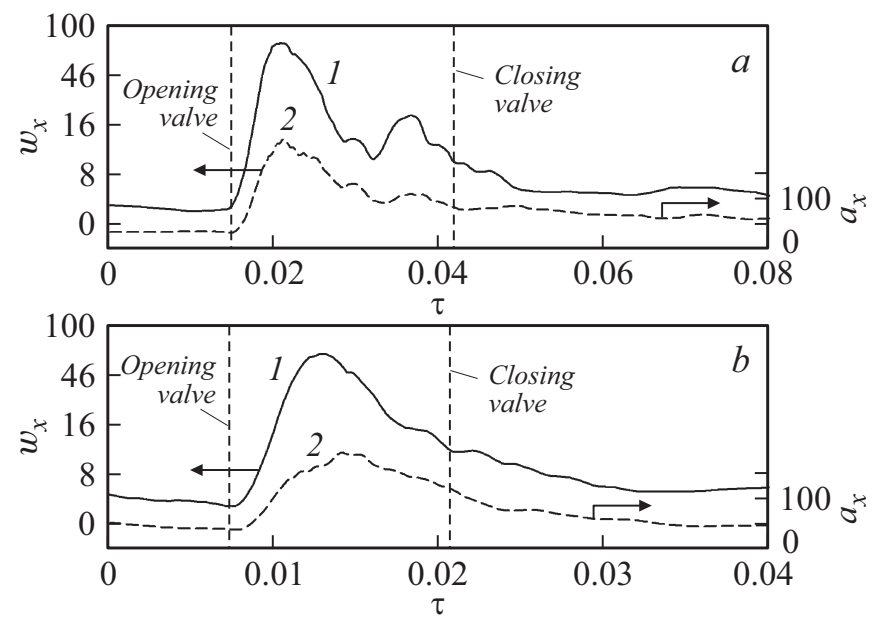

Рис. 5. Зависимости локальных $\left(l_{x}=110 \mathrm{~mm}\right)$ скорости потока воздуха $w_{x}(1)$ и коэффициента теплоотдачи $\alpha_{x}(2)$ от времени $\tau$ в выпускном трубопроводе круглого поперечного сечения при разных частотах вращения $n: a-n=1500 \mathrm{rpm}$; $b-n=3000 \mathrm{rpm}$. 

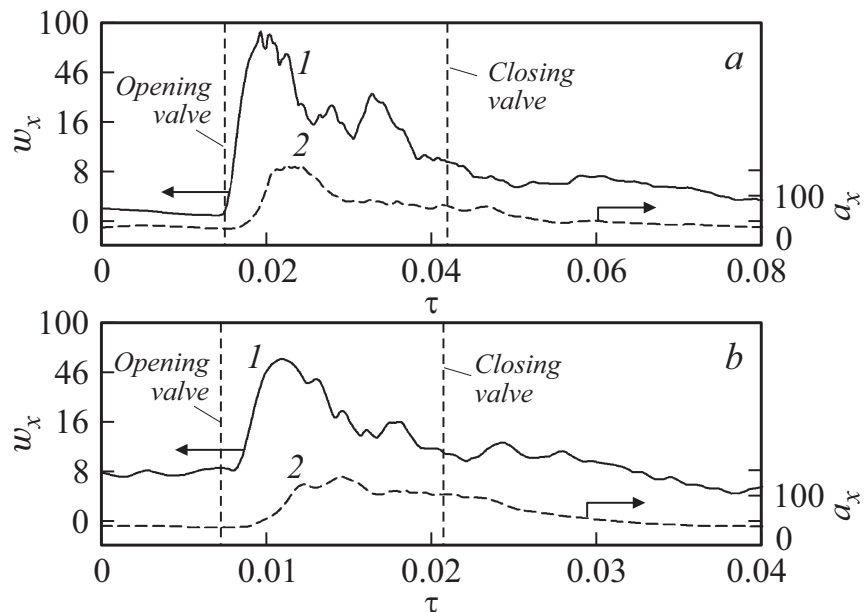

Рис. 6. Зависимости локальных $\left(l_{x}=110 \mathrm{~mm}\right)$ скорости потока воздуха $w_{x}(1)$ и коэффициента теплоотдачи $\alpha_{x}(2)$ от времени $\tau$ в выпускном трубопроводе с участком с треугольным поперечным сечением при разных частотах вращения $n$ : $a-n=1500 \mathrm{rpm} ; b-n=3000 \mathrm{rpm}$.

Также рассматривались профилированные участки той же конфигурации, т.е. с поперечными сечениями в форме круга, квадрата и равностороннего треугольника. Во всех случаях эквивалентный (гидравлический) диаметр $d_{e}$ участка равнялся $30 \mathrm{~mm}$, а его длина составляла приблизительно 30\% от общей длины выпускной системы.

В целом экспериментальные исследования процессов в выпускной системе ДВС выявили те же качественные закономерности, что и во впускной системе. Установлено, что пульсации скорости потока газов наиболее выражены при низких частотах вращения коленчатого вала при всех конфигурациях выпускного трубопровода (рис. 5 и 6). Скорость потока газов после закрытия выпускного клапана не становится равной нулю и наблюдаются некоторые флуктуации скорости [21]. Схожий эффект наблюдался и для впускной системы (см. выше).

Установлено, что в случае использования в выпускной системе двигателя профилированного участка наблюдается возросший объемный расход газа через систему (увеличивается пропускная способность) при всех начальных условиях, что, вероятно, связано со стабилизирующим влиянием вихревых структур, образующихся в углах квадратного и треугольного участков [21]. Увеличение расходных характеристик через выпускную систему с профилированным участком, по мнению авторов, приведет к улучшению очистки цилиндров от отработавших газов, что в перспективе должно вызвать повышение мощности двигателя.

Перемены в газодинамических факторах оказывают воздействие на интенсивность мгновенной локальной теплоотдачи в выпускном трубопроводе, в частности, заключающееся в возникновении запаздывания во вре- мени интенсивности изменения мгновенной теплоотдачи от изменения скорости потока воздуха (рис. 5 и 6). При этом величина запаздывания увеличивается с ростом частоты вращения коленчатого вала, что характерно для всех начальных условий и для всех исследуемых конфигураций трубопроводов. Следует отметить, что противоположный эффект наблюдался во впускных системах поршневых двигателей, где величина запаздывания, наоборот, уменьшалась с ростом частоты вращения вала. По-видимому, это объясняется разным физическим механизмом процессов впуска и выпуска (см. выше).

Установлено, что величина запаздывания во времени интенсивности изменения мгновенной теплоотдачи от изменения скорости потока воздуха уменьшается при использовании трубопроводов с профилированными участками, что объясняется изменением газодинамических условий теплообмена.

Также можно отметить, что вид кривой изменения локального коэффициента теплоотдачи становится более гладким при высоких значениях частоты вращения коленчатого вала двигателя (рис. 6). При этом, как и в случае с выпускным трубопроводом постоянного круглого поперечного сечения, в профилированных каналах с увеличением частоты вращения коленчатого вала наблюдается сглаживание зависимости $\alpha_{x}=f(\tau)$ (рис. 7).

Таким образом, можно констатировать, что с ростом частоты вращения коленчатого вала газодинамика процесса выпуска меняется и происходит смена режима течения потока. Это соответственно приводит к трансформации зависимости локального коэффициента теплоотдачи от времени, что характерно для всех исследуемых конфигураций выпускного трубопровода.

Из рис. 7 также видно, что интенсивность теплоотдачи в выпускном трубопроводе круглого попереч-
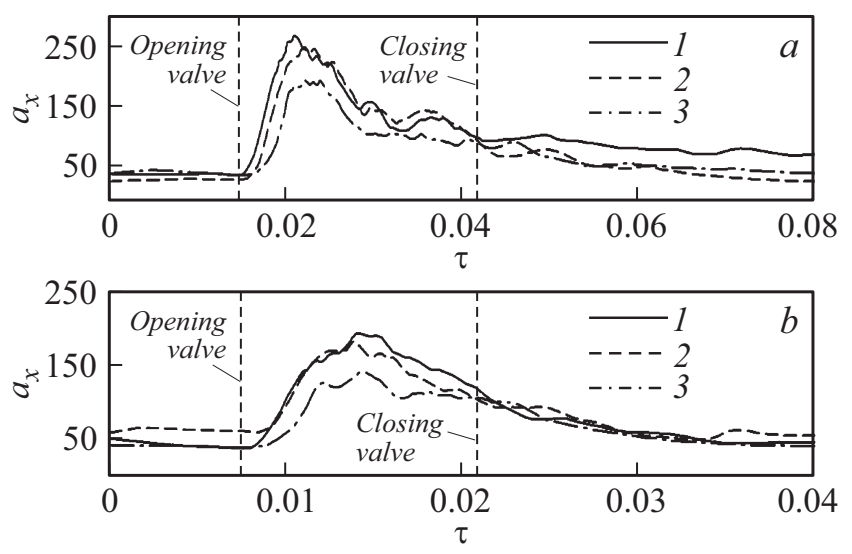

Рис. 7. Зависимость мгновенного локального $\left(l_{x}=110 \mathrm{~mm}\right)$ коэффициента теплоотдачи $\alpha_{x}$ от времени $\tau$ в выпускном трубопроводе с разными профилированными участками при разных частотах вращения $n: a-n=1500 \mathrm{rpm} ; \quad b-$ $n=3000 \mathrm{rpm}$. Поперечное сечение участка: $1-$ круг, $2-$ квадрат, 3 - треугольник. 
ного сечения и трубопроводе с участком с квадратным поперечным сечением фактически одинакова (отличия составляют около $5-10 \%$ и находятся в пределах погрешности). Это характерно для всех начальных условий и частот вращения коленчатого вала. Вместе с тем в выпускном трубопроводе с участком треугольного поперечного сечения происходит снижение интенсивности и максимальных значений локального коэффициента теплоотдачи: это снижение $\alpha_{x}$ находится в диапазоне $10-25 \%$ при частотах вращения $n$ от 600 до $1500 \mathrm{rpm}$ и в диапазоне $20-30 \%$ при $n=3000 \mathrm{rpm}$.

С прикладной точки зрения обнаруженный эффект свидетельствует о том, что при использовании выпускного трубопровода с профилированным участком в форме равностороннего треугольника в стенки трубопровода „уходит “ меньше теплоты, при этом соответственно снижается тепловая напряженность элементов выпускной системы и увеличивается продолжительность ее службы (моторесурс).

\section{Заключение}

По результатам экспериментального исследования можно сделать следующие основные выводы.

1. Установлено влияние режимных факторов (частоты вращения, давления в цилиндре) и поперечного профилирования впускного и выпускного трубопроводов на газодинамические и тепломеханические характеристики потоков применительно к поршневым двигателям.

2. Поперечное профилирование впускного трубопровода двигателя снижает интенсивность локальной теплоотдачи в диапазоне 5-20\% в зависимости от частоты вращения коленчатого вала поршневого двигателя, что приведет к:

- снижению подогрева воздуха во впускной системе в среднем на 30\% (в перспективе это должно вызвать повышение мощности вследствие лучшего наполнения цилиндра воздухом);

- уменьшению температурных напряжений деталей и узлов впускной системы, что соответственно повысит их надежность.

3. Поперечное профилирование выпускного трубопровода поршневого двигателя снижает интенсивность локальной теплоотдачи на величину до $30 \%$, что приведет к снижению тепловой напряженности основных элементов выпускной системы.

4. Полученные новые данные расширяют физические представления о газодинамике и теплообмене нестационарных потоков и могут быть применены при разработке методов модернизации газовоздушных систем поршневых двигателей.

Вместе с тем, учитывая специфику формирования турбулентных структур [22], следует отметить, что оптимальные геометрические характеристики впускной и выпускной систем, включая длину и местоположение профилированных участков, равно как и достигаемый в результате их использования положительный эффект, можно количественно установить только на основе дополнительных испытаний при создании или модернизации конкретной энергетической установки.

Работа выполнена при поддержке РФФИ в рамках научного проекта № 16-38-00004 мол_а.

\section{Список литературы}

[1] Драганов Б.Х., Круглов М.Г., Обухова В.С. Конструирование впускных и выпускных каналов двигателей внутреннего сгорания. Киев: Вища шк. Головное изд-во, 1987. 175 с.

[2] Heywood J.B. Internal combustion engine fundamentals. NY: McGraw-Hill, 1988. 458 p.

[3] Жилкин Б.П., Лашманов В.В., Плотников Л.В., Шестаков Д.С. Совершенствование процессов в газовоздушных трактах поршневых двигателей внутреннего сгорания: монография. Екатеринбург: Изд-во Урал. ун-та, 2015. 228 с.

[4] Шароглазов Б.А., Шишков В.В. Поршневые двигатели: теория, моделирование и расчет процессов; учебник по курсу „Теория рабочих процессов и моделирование процессов в двигателях внутреннего сгорания“. Челябинск: Издательский центр ЮУрГУ, 2011. 525 с.

[5] Кавтарадзе Р.3. Теория поршневых двигателей. Специальные главы. Москва: Изд-во МГТУ им. Н.Э. Баумана, 2008. $720 \mathrm{c}$.

[6] Гленсдорф П., Пригожин И. Термодинамическая теория структуры, устойчивости и флуктуаций. М.: Мир, 1973. $279 \mathrm{c}$.

[7] Liao N.S., Wang C.C. // $1^{\text {st }}$ World Conf. - Exp. Heat Transfer, Fluid Mechan. Thermodynamics. 1988. P. 536-542.

[8] Симаков Н.Н. // ЖТФ. 2016. Т. 86. Вып. 12. С. 42-48.

[9] Sucec J. // Int. J. Heat Mass Transfer. 2002. N 45 (8). P. 16311642.

[10] Гольиман А.Е., Давлетшин И.А., Михеев Н.И., Паерелий A.A. // Теплофизика и аэромеханика. 2015. Т. 22. № 3. C. 333-342.

[11] Park J.S., Taylor M.F., McEligot D.M. Heat Transfer to Pulsating Turbulent Gas Flow. // Proc. $7^{\text {th }}$ Intern. Heat Transfer Conf. 1982. Vol. 3. P. 105-110.

[12] Пригожин И. Неравновесная статистическая механика. М.: Мир, 1964. 314 с.

[13] Плохов С.Н., Плотников Л.В., Жилкин Б.П. Патент на полезную модель № 81338 RU (G01P 5/12). 2009.

[14] Skelly B.T., Miller D.R., Meyer T.H. // Bound.-Layer Meteorol. 2002. N 105 (2). P. 275-304.

[15] Повх И.Л. Аэродинамический эксперимент в машиностроении. Л.: Машиностроение, 1974. 480 с.

[16] Брэдшоу П. Введение в турбулентность и ее измерение. M., 1974. 282 c.

[17] Foss J.F. et al. // Measurement Science and Technology. 2004. N 15 (11). P. 2248-2255.

[18] Кутателадзе С.C. Теплопередача и гидродинамическое сопротивление: Справочное пособие. М.: Энергоатомиздат, 1990. 367 c.

[19] Идельчик И.Е. Аэрогидродинамика технологических аппаратов. (Подвод, отвод и распределение потока по сечению аппаратов). М.: Машиностроение, 1983. 351 с. 
[20] Плотников Л.В., Жилкин Б.П., Бродов Ю.М. // Известия вузов. Машиностроение. 2015. № 12 (669). С. 35-44.

[21] Plotnikov L.V., Zhilkin B.P., Brodov Y.M. // Proc. Engin. 2016. Vol. 150. P. 111-116.

[22] Климонтович Ю.Л. Турбулентное движение и структура хаоса: новый подход к статистической теории открытых систем. М.: Наука, 1990. 320 с. 